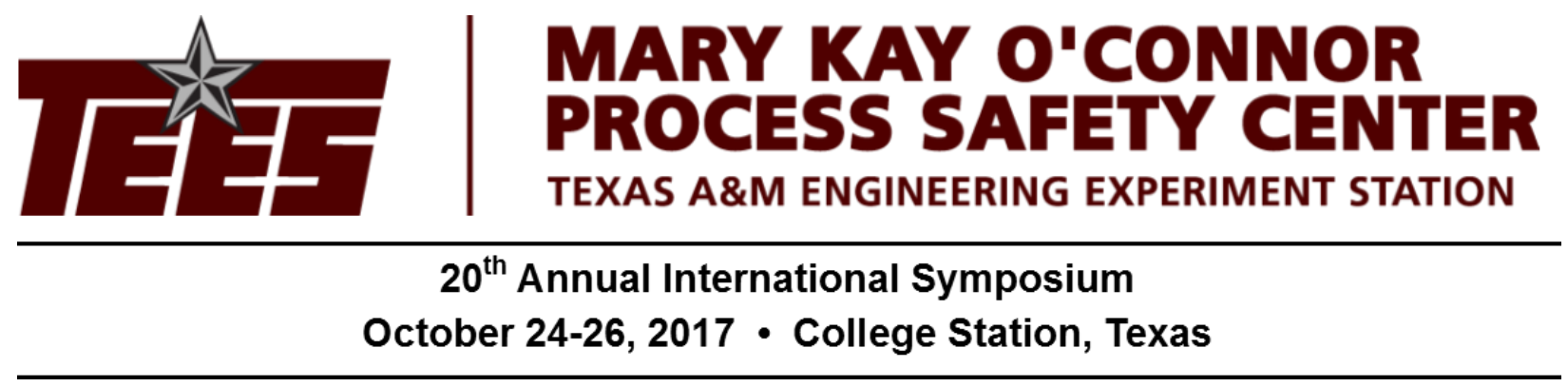

\title{
Comparison of Large-Scale Vented Deflagration Tests to CFD Simulations for Partially Congested Enclosures
}

Peter A. Diakow, Project II Consultant, Baker Engineering and Risk Consultants, Inc.

J. Kelly Thomas, Senior Principal Engineer, Baker Engineering and Risk Consultants, Inc.

Emiliano Vivanco, Project I Consultant, Baker Engineering and Risk Consultants, Inc.

\author{
Mary Kay O’Connor Process Safety Center \\ Artie McFerrin Department of Chemical Engineering \\ Texas A\&M University \\ College Station, Texas 77843-3122 \\ †Presenter E-mail: pdiakow@BakerRisk.com
}

\begin{abstract}
This paper presents a comparison between the results from a test program carried out to characterize the blast load environment within BakerRisk's Deflagration Load Generator (DLG) test rig, and predictions made using the FLACS computational fluid dynamics (CFD) code. The test data was also compared to internal peak pressure predictions made using the National Fire Protection Association's Standard on Explosion Protection by Deflagration Venting (NFPA 68) [1]. The purpose of these tests was to provide data for comparison with standard methods used to predict internal blast loads in a vented deflagration. The tests also provided a characterization of the internal DLG blast load environment for equipment qualification testing.

The DLG test rig is 48 feet wide $\times 24$ feet deep $\times 12$ feet tall and is enclosed by three solid walls, a roof, and floor, with venting through one of the long walls (i.e., 48-foot by 12 -foot). During testing, the venting face of the rig was sealed with a 6 mil $(0.15 \mathrm{~mm})$ thick plastic vapor barrier to allow for the formation of a near-stoichiometric propane-air mixture throughout the rig. The flammable gas cloud was ignited near the center of the rear wall. Congestion inside the rig was provided by a regular array of vertical cylinders (2-inch outer diameter) that occupied the rear half of the rig; the front half of the rig was uncongested (i.e., as would be the case for equipment qualification testing). Forty-three pressure transducers were deployed internal and external to the rig to measure blast pressure histories.
\end{abstract}

Three series of tests were conducted with congestion levels varying from an area blockage ratio (ABR) of $11 \%$ in Test Series A to ABR values of $7.6 \%$ and $4.2 \%$, respectively, in Test Series $B$ and $C$. The obstacle-to-enclosure surface area ratio $\left(A_{r}\right)$, a perameter used within the NFPA 68 
correlations to quantify congestion, was equal to $0.45,0.32$, and 0.17 for test series $\mathrm{A}$, B and $\mathrm{C}$, respectively. The peak pressures and impulses for each test are provided, along with pressure histories internal and external to the rig for selected tests. Comparisons of the test data to predictions made using the FLACS CFD code and NFPA 68 venting correlations are also provided. 


\section{Introduction}

The primary objective of these tests was to characterize the blast loads produced by a vapor cloud explosion (VCE) within a partially congested, vented enclosure and compare the measured peak pressures, impulse (duration) and wave shape to standard prediction methods. The FLACS CFD code and the NFPA 68 correlations were identified as two standard prediction methods for determining vented deflagration blast loads.

The data collected for the partially congested environment (congestion restricted to the rear half of the DLG) is also applicable for equipment qualification testing, where specimens would be placed into the uncongested region of the DLG during testing. External blast wave propagation data was also collected and compared to the FLACS CFD code predictions. Six tests (two tests for each of three test series) were performed. The test matrix is provided as Table 1.

Table 1. Large Scale partially congested vented deflagration test matrix

\begin{tabular}{|c|c|c|c|c|c|}
\hline $\begin{array}{c}\text { Test } \\
\text { Series }\end{array}$ & $\begin{array}{c}\text { Flammable } \\
\text { Volume }\end{array}$ & $\begin{array}{c}\text { Congested } \\
\text { Volume }\end{array}$ & $\begin{array}{c}\text { Area Blockage } \\
\text { Ratio } \\
\text { (Congested } \\
\text { Region) }\end{array}$ & $\begin{array}{c}\text { Volume } \\
\text { Blockage Ratio } \\
\text { (Full Rig) }\end{array}$ & $\mathbf{A}_{\mathbf{r}}$ \\
\hline $\mathbf{A}$ & $100 \%$ & $50 \%$ & $11 \%$ & $0.50 \%$ & 0.45 \\
\hline $\mathbf{B}$ & $100 \%$ & $50 \%$ & $7.60 \%$ & $0.30 \%$ & 0.32 \\
\hline $\mathbf{C}$ & $100 \%$ & $50 \%$ & $4.20 \%$ & $0.20 \%$ & 0.17 \\
\hline
\end{tabular}

\section{Test Rig Configuration}

The test rig is an enclosure with three solid walls, a roof, and floor, measuring 48 feet wide, 24 feet deep, and 12 feet tall. Venting was allowed through one of the long walls (i.e., 48 -foot by 12-foot). The venting face of the rig was sealed with a 6 mil thick plastic vapor barrier, which released (i.e., tore open) at approximately 0.1 psig. Figure 1 shows a photo of the test rig with this barrier installed. The vapor barrier allowed for the formation of a near-stoichiometric (slightly fuel-rich) propane-air mixture inside the test rig which was ignited in the center of the rear wall, opposite the venting surface.

Congestion inside the rig was provided by a regular array of vertical cylinders (2-inch outer diameter) that occupied the rear half of the rig; the front half of the rig was uncongested, which is representative of a partially congested process enclosure, and is also the configuration used for equipment qualification testing inside the DLG. The congestion pattern was progressively reduced from Test Series A to B and from Test Series B to C, as shown by the area and volume blockage ratios (ABR and VBR) listed in Table 1. Congested environments with ABR less than 10\% are considered low congestion in the Baker-Strehlow-Tang blast prediction methodology [2]. The obstacle-to-enclosure surface area ratio $\left(\mathrm{A}_{\mathrm{r}}\right)$, being a function of the congestion and the enclosure, also changed between test series; $\mathrm{A}_{\mathrm{r}}$ was equal to $0.45,0.32$, and 0.17 for test series $\mathrm{A}, \mathrm{B}$ and $\mathrm{C}$, respectively. Figure 2 shows the congestion array for all test series. 


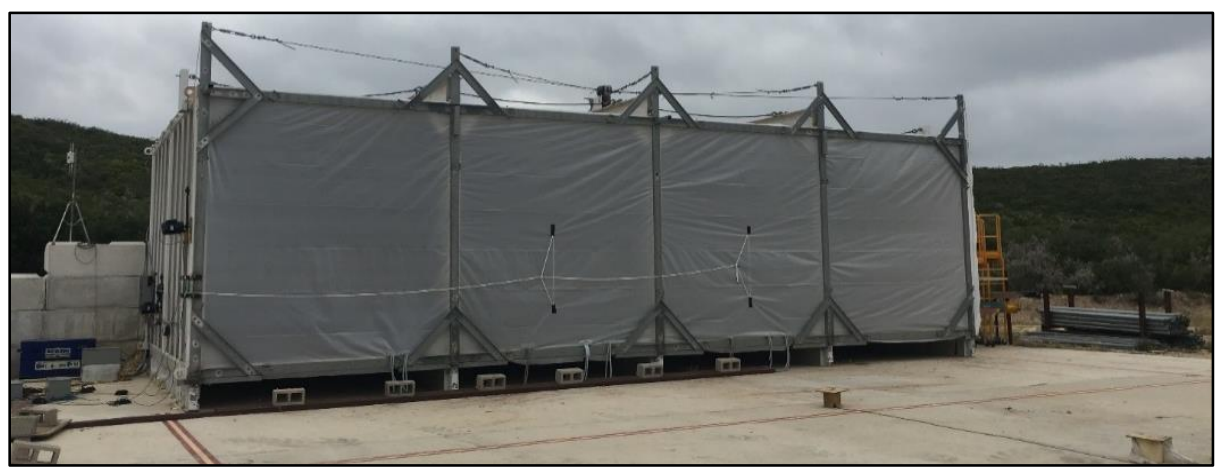

Figure 1. Test rig venting configurations for all test series

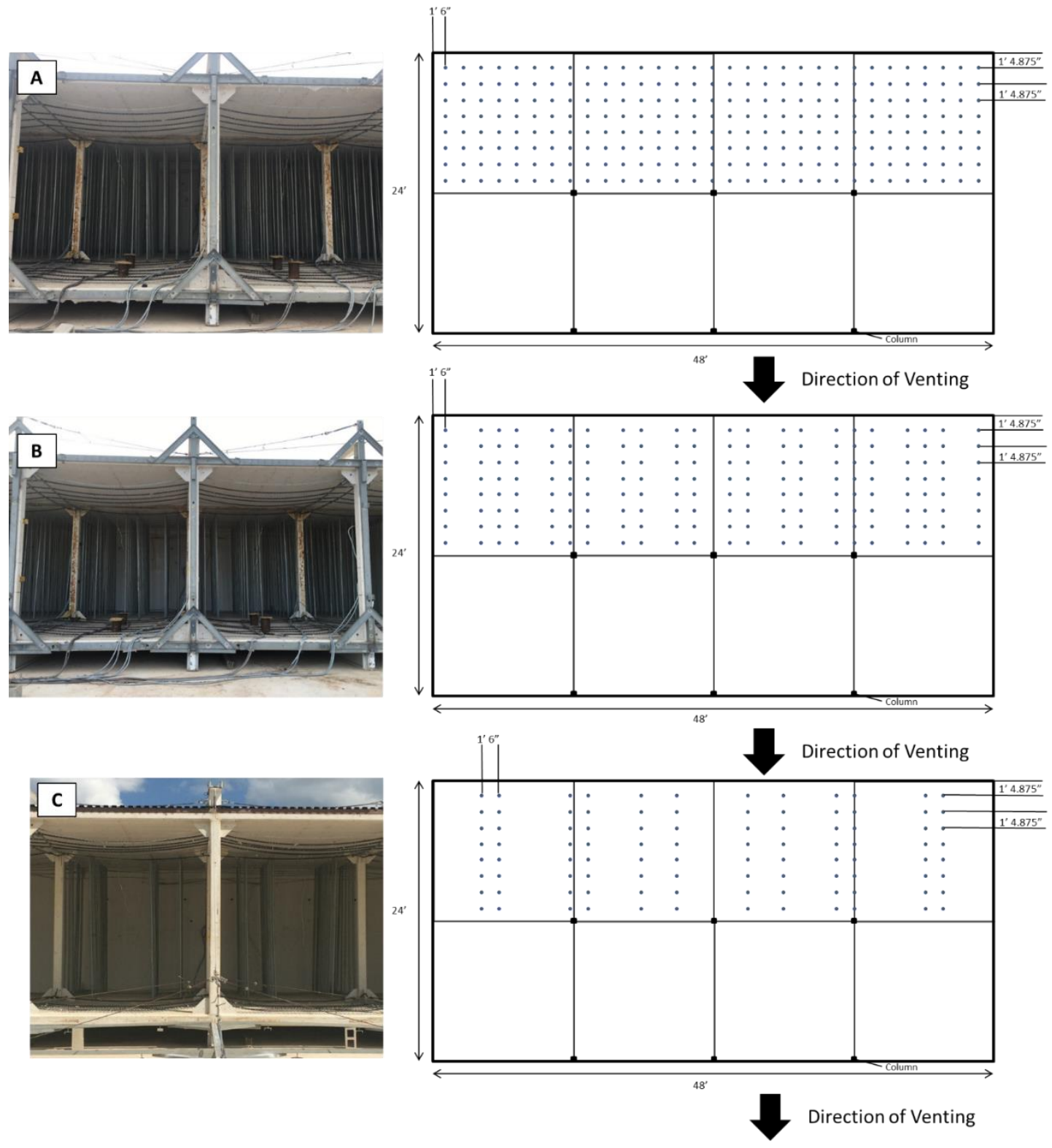

Figure 2. Test rig congestion configuration for Test Series A, B and C 
Twenty-seven pressure transducers were fielded within the test rig, and sixteen transducers were fielded external to the rig. Figure 3 and Figure 4 show the internal pressure transducer locations used during this test program. Transducers were located on the DLG floor, ceiling, walls, and six interior DLG columns. Floor, ceiling, and column transducers were distributed symmetrically along a vertical centreline as viewed from Figure 4. Wall transducers were distributed asymmetrically, with five transducers located on the left (east) side of the DLG, and two transducers located on the right (west) side, as viewed from Figure 4.

External to the rig, one lane of eight pressure transducers was deployed along the rig centreline and aligned in the direction of blast wave propagation, the remaining eight transducers were split into two lanes extending from a corner of the DLG. A high definition (30 fps) camera was deployed to record fireball propagation. The layout of the exterior pressure transducers are shown in Figure 5.

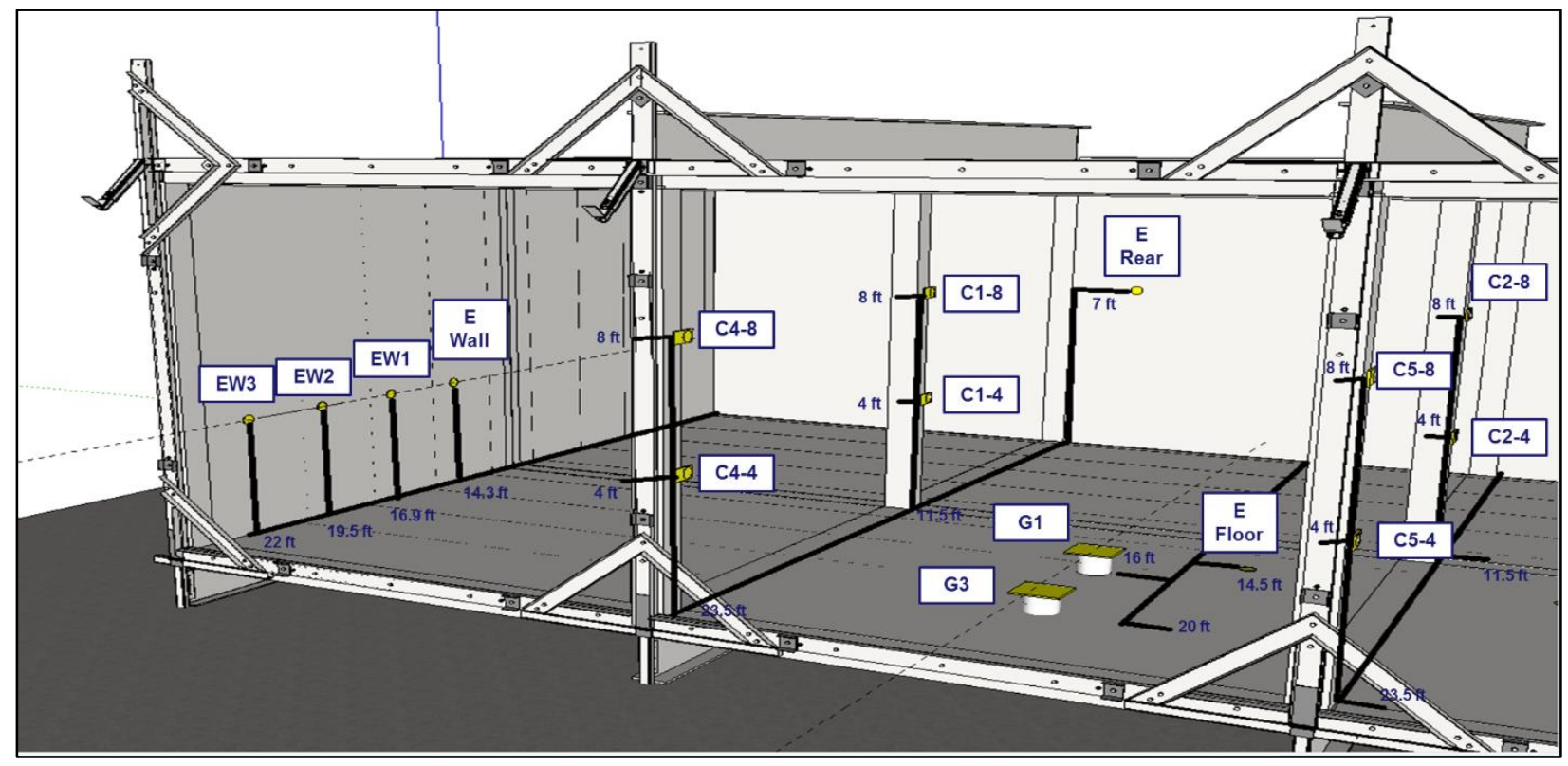

Figure 3. Internal pressure transducer layout (1 of 2) 


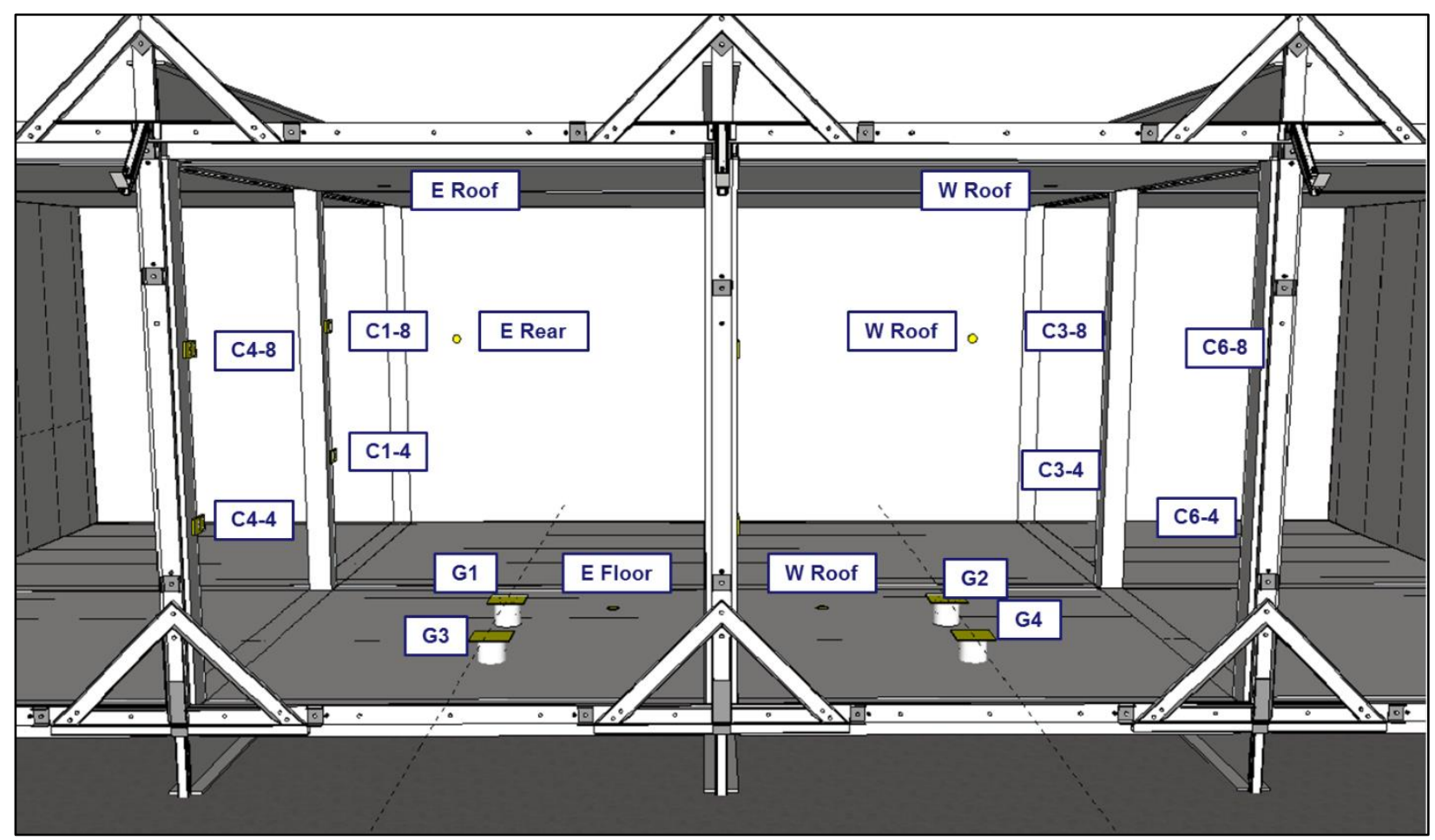

Figure 4. Internal pressure transducer layout (2 of 2)

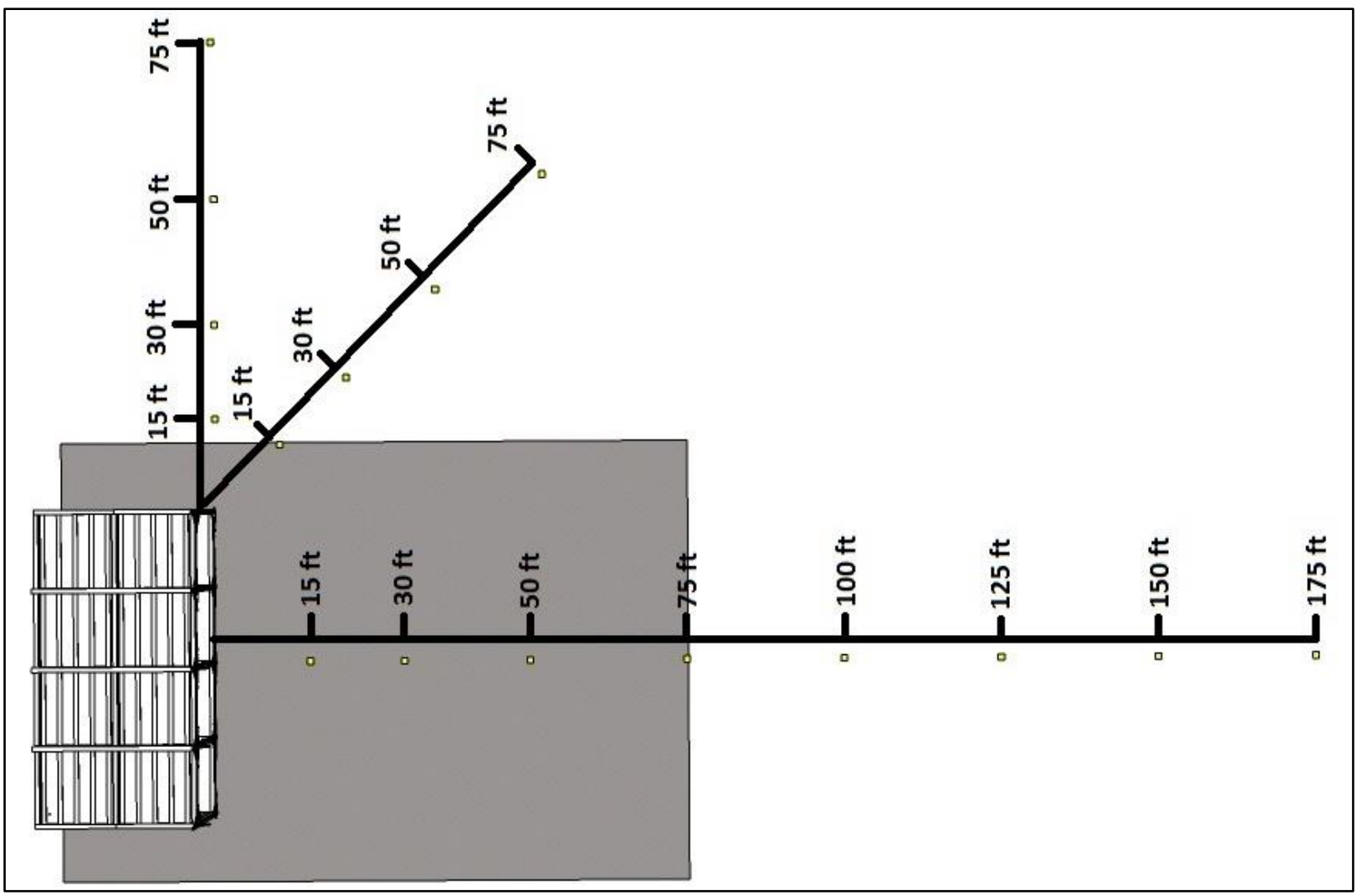

Figure 5. External pressure transducer layout 


\section{FLACS Simulations}

Blind (i.e., pre-test) CFD simulations were performed using the FLACS (Flame Acceleration Simulator) code. FLACS is a CFD tool commonly used in industry for VCE simulations, as well as dispersion analysis and VCE mitigation option evaluations. FLACS solves conservation equations for mass, momentum, enthalpy, turbulence and species/combustion on a 3D Cartesian grid. The proper representation of geometry (obstacles and structures) is a key aspect of the development of the FLACS code. Obstacles such as structures and pipes are represented as area porosities (the opposite of blockages) on control volume (CV) faces and are represented as volume porosities in the interior of the CV. CV surfaces and CV volumes are each either fully open, fully blocked, or partly blocked. For the partly blocked surfaces or volumes, the porosity is defined as the fraction of the area/volume that is available for fluid flow. The resulting porosity model is used to calculate flow resistance and turbulence source terms from small objects, as well as the flame speed enhancement arising from flame folding in the sub-grid wake. An overview of the FLACS geometry created for these simulations is shown in Figure 6.

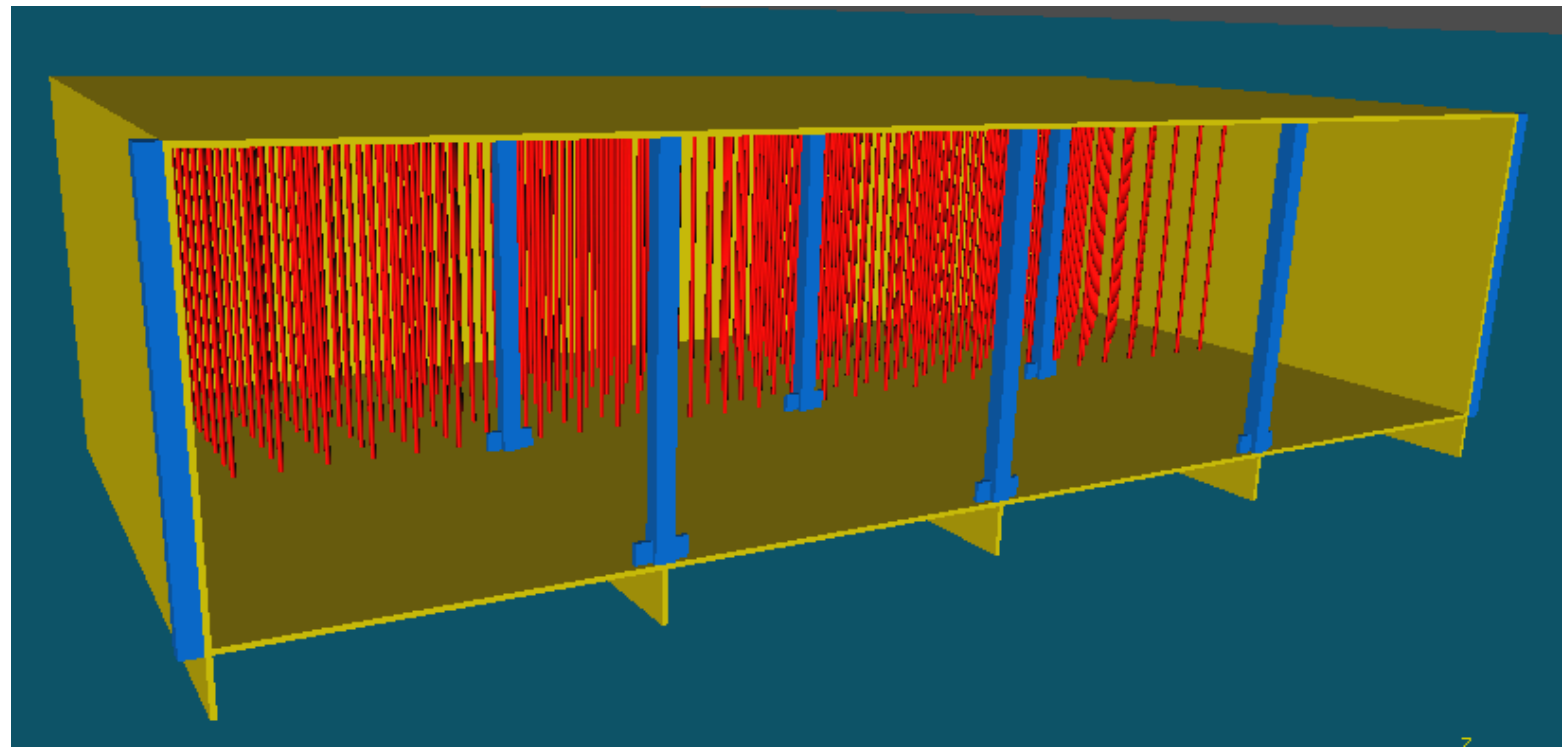

Figure 6. DLG rig model created for FLACS simulations

This 3D geometry includes monitor points that represent the physical pressure transducer locations from the field tests. A view of some of the monitor points used in the simulations is shown in Figure 7. The flammable volume, flammable cloud composition and ignition location used for the simulations were the same as for the field tests. The computational mesh was created following the guidelines in the FLACS user's manual [3] which states that for confined rooms filled with gas from wall to wall the combustion region must be resolved by a minimum of 5-6 grid cells in the smallest direction of flame acceleration. Thus, for the DLG rig the smallest dimension was 12 feet (height), resulting in a grid cell size of 2 feet. The grid cells used were cubical in shape, resulting in an internal mesh 6 cells tall, 12 cells deep and 24 cells wide. The same cells size was used for the mesh external to the rig. 


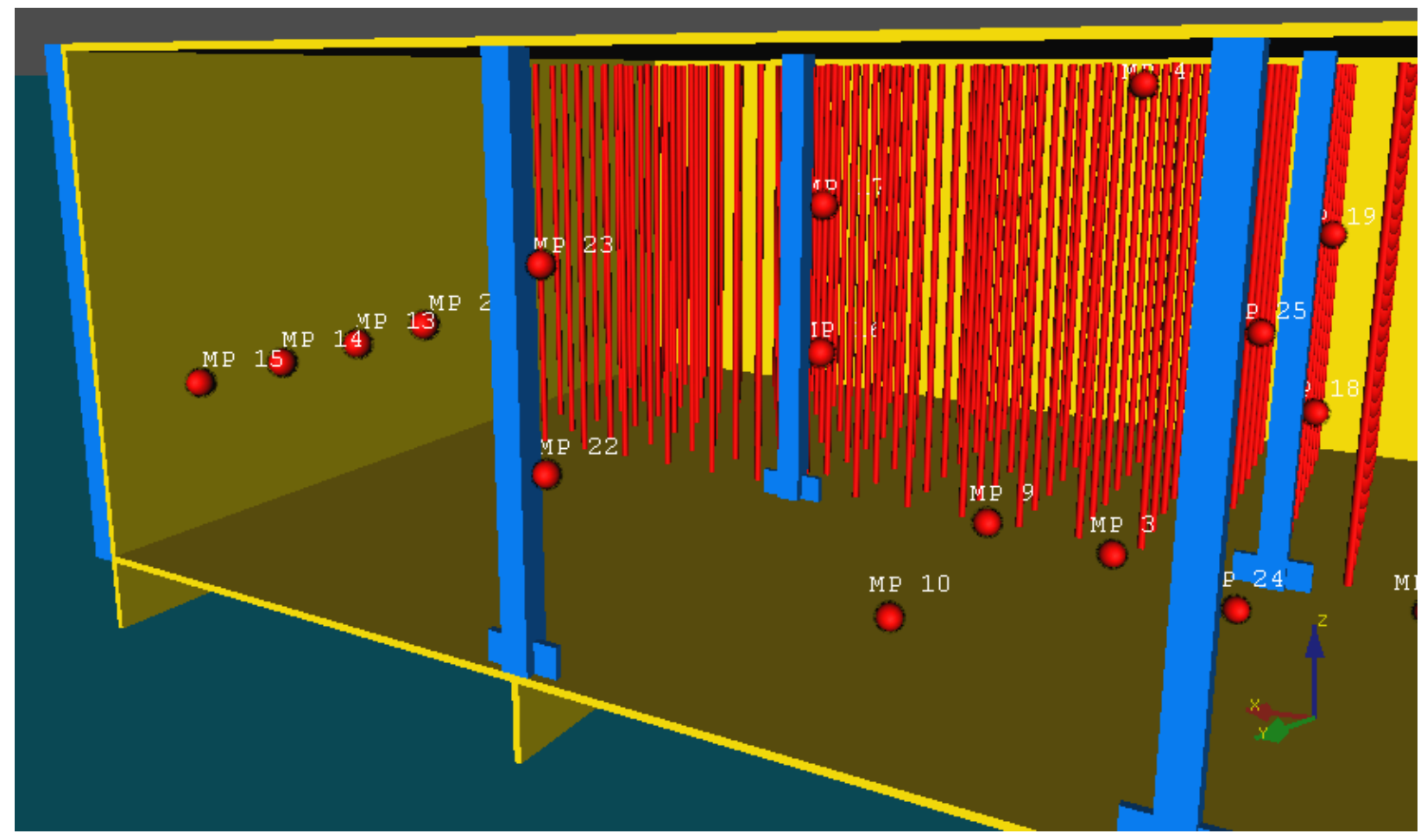

Figure 7. Internal monitor points layout used in FLACS simulations

\section{Results and Discussion}

\section{Internal pressure}

The peak pressures measured by all internal transducers were used to determine an average internal peak pressure for each test, and subsequently for each test series. The maximum impulse (integration of pressure with respect to time) for each pressure transducer was calculated based on the positive phase of the measured pressure history. The average internal impulse was then determined for each test and series.

Exemplar pressure traces at the floor transducer locations for test A02 (ABR 11\%, VBR 0.5\%) are provided in Figure 8. Figure 9 provides pressure traces from the FLACS simulations for test series $\mathrm{A}$ at the same locations. The floor transducers were located near grade, in the region where test specimens would be located during equipment qualification testing, so that the wave shape, peak pressure and impulse (duration) for these locations are of particular interest. The pressure traces from Figure 8 (test data) and Figure 9 (FLACS simulation) show similar wave shape and duration. However, the FLACS peak pressure predictions are approximately a factor of 3 larger than the test data.

Figure 10 and Figure 11 show peak pressure and impulse, respectively, at the floor transducer locations for all test series (test data and FLACS simulations). The peak pressure and impulse at the floor transducer locations decreased as the congestion inside the DLG became less dense (i.e., from series $\mathrm{A}$ to $\mathrm{B}$ and from series $\mathrm{B}$ to $\mathrm{C}$ ). The trends between the tests shown in 
Figure 10 and Figure 11 are similar between the test data and FLACS predictions; however, the FLACS predictions are significantly conservative for all series. The peak pressure and impulse data from the floor transducer locations show that centrally peaked free-field blast loads of up to 5.4 psig and 230 psi-ms ( 85 ms duration) can be applied to test specimens inside the DLG.

Exemplar pressure traces at the wall and column pressure transducer locations, for Test A02 (ABR 11\%, VBR 0.5\%) are provided in Figure 12. Figure 13 provides pressure traces from the FLACS simulations for Test Series $A$ at the wall and column pressure transducer locations. The wall pressure transducers were located 4 feet above grade, whereas the column transducers were located at 4 feet and 8 feet above grade. Similar to the floor transducers, the FLACS simulations predicted similar wave shape, durations and pressure trends for the vertically oriented pressure transducers, however the predicted peak pressures were conservative compared to the test data for all series.

Figure 10 and Figure 12 shows that the wave shape, peak pressure and impulse (duration) are very similar at the floor, at the 4-foot elevation and at the 8-foot elevation within the DLG, indicating a reasonably symmetrical blast loading across these locations.

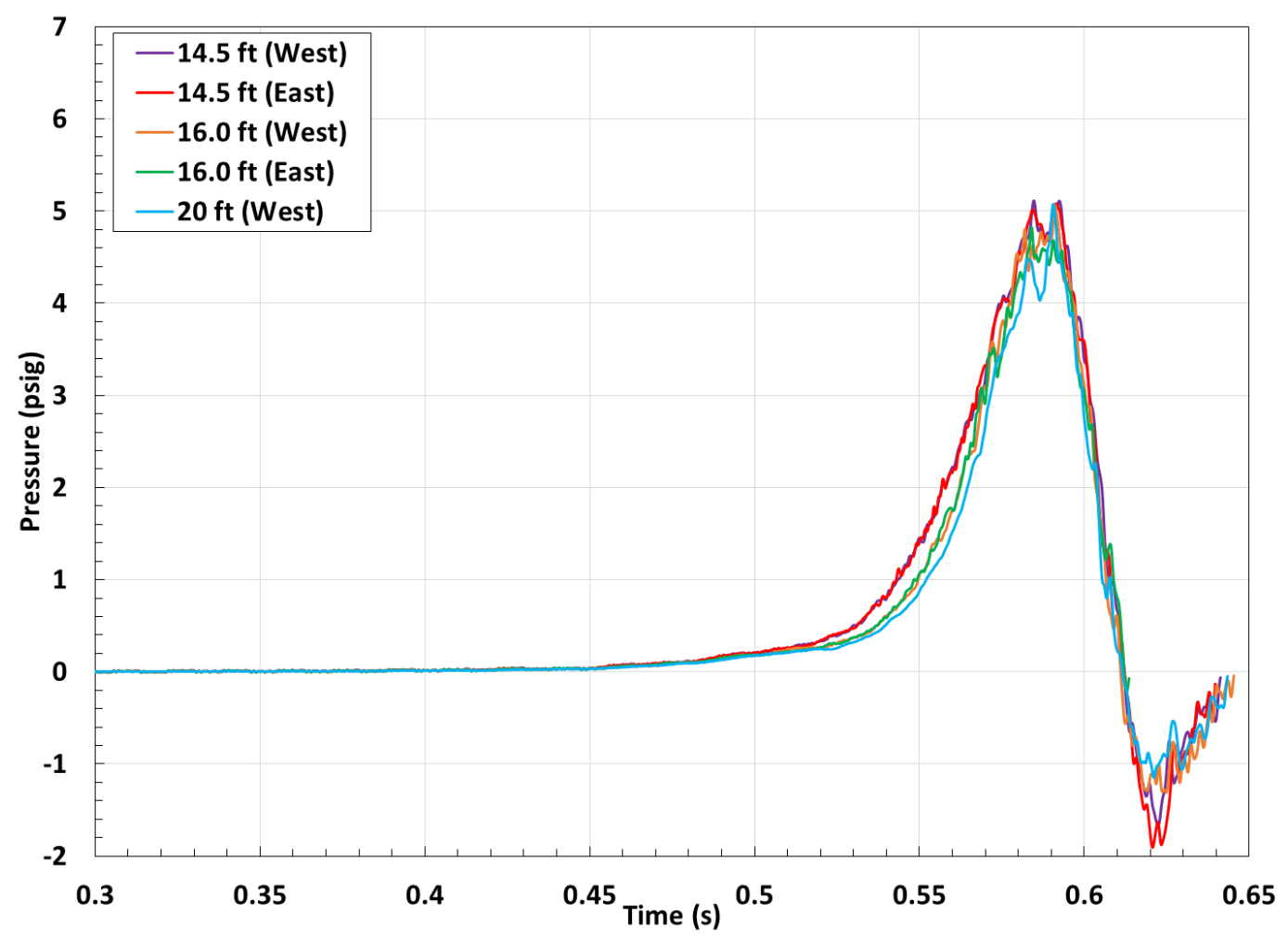

Figure 8. Pressure history at the floor pressure transducers for Test A02 


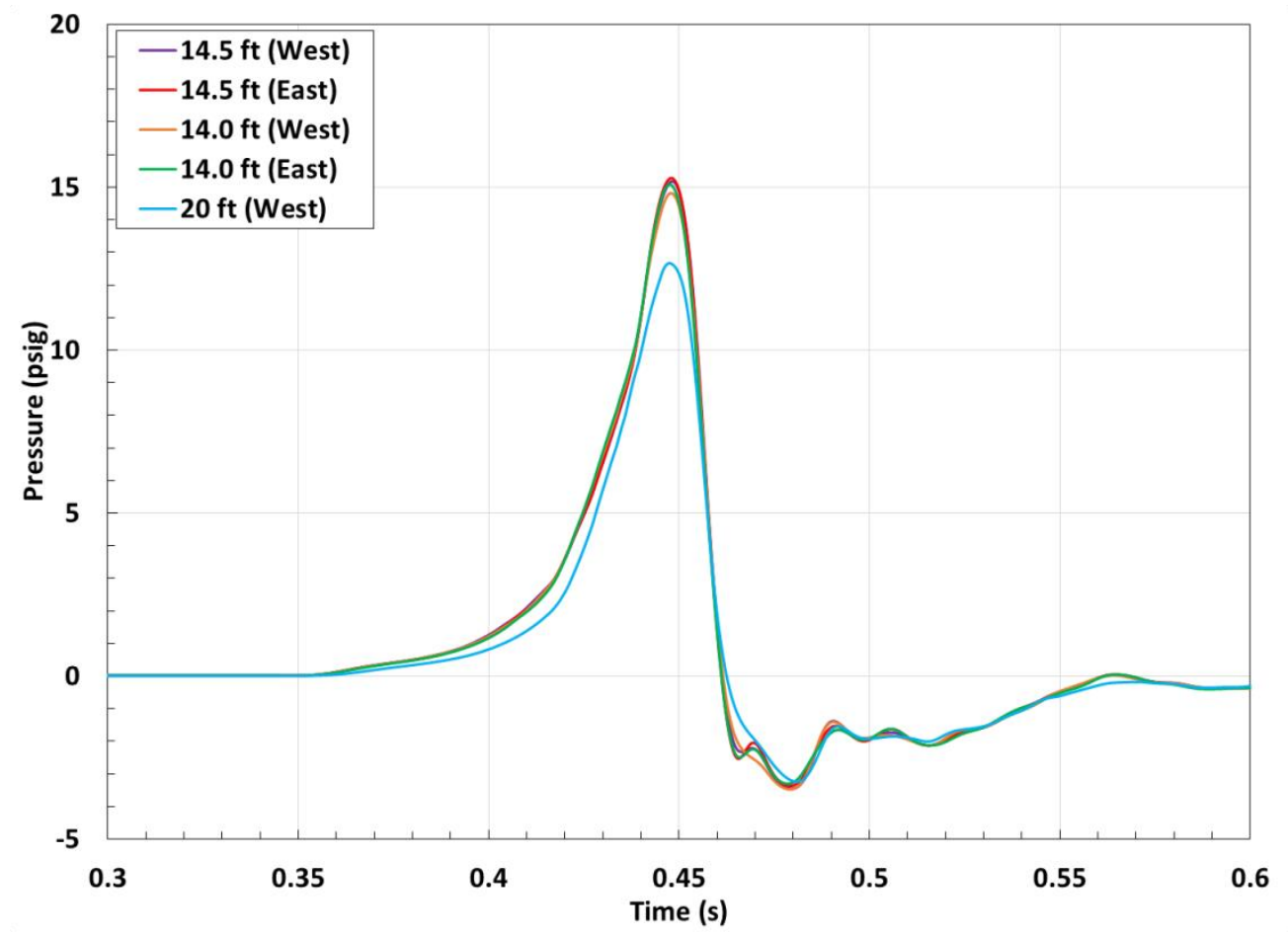

Figure 9. FLACS predicted pressure histories at the floor transducers for Series A

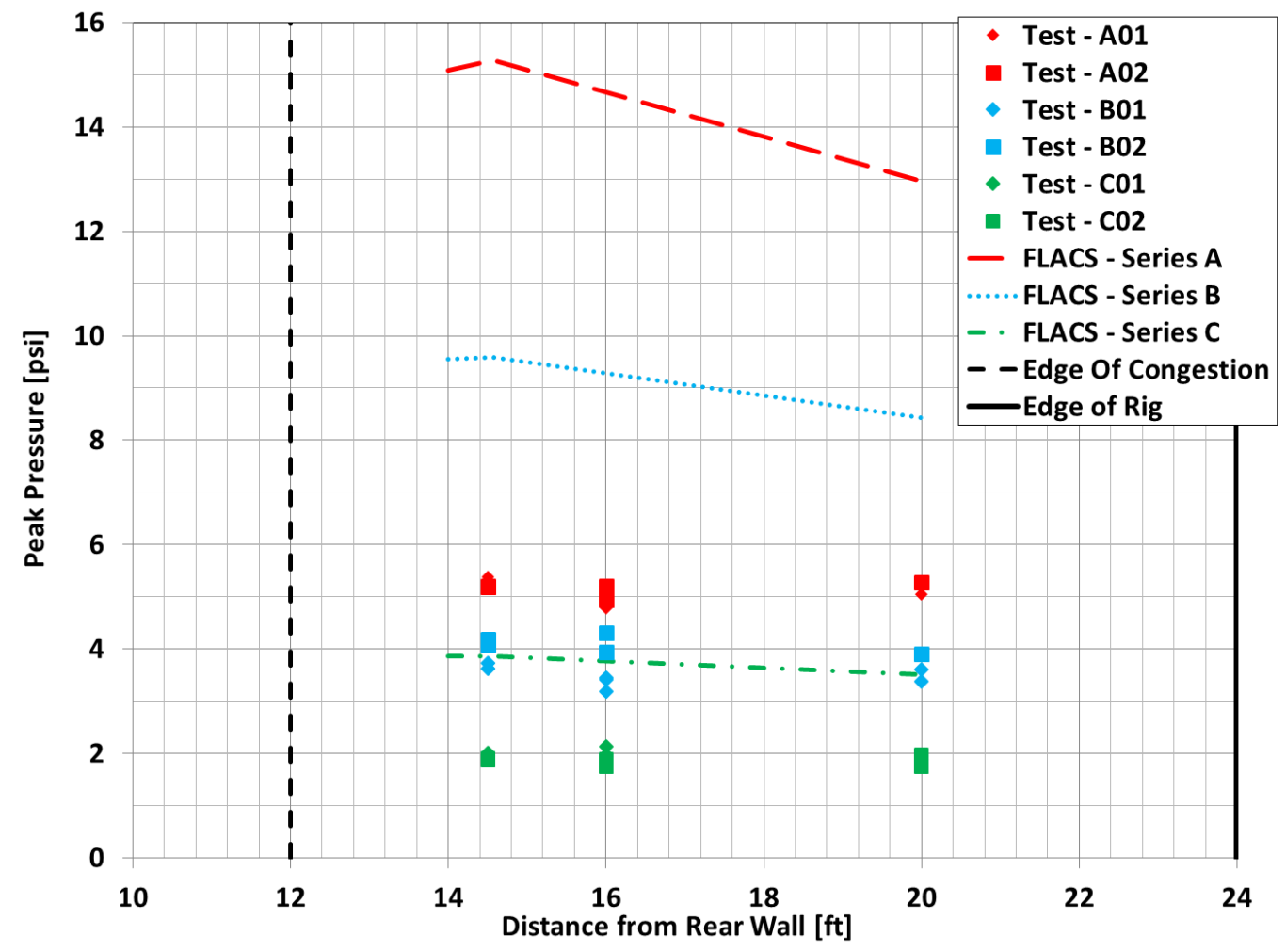

Figure 10. Internal peak pressure at the floor for all test series 


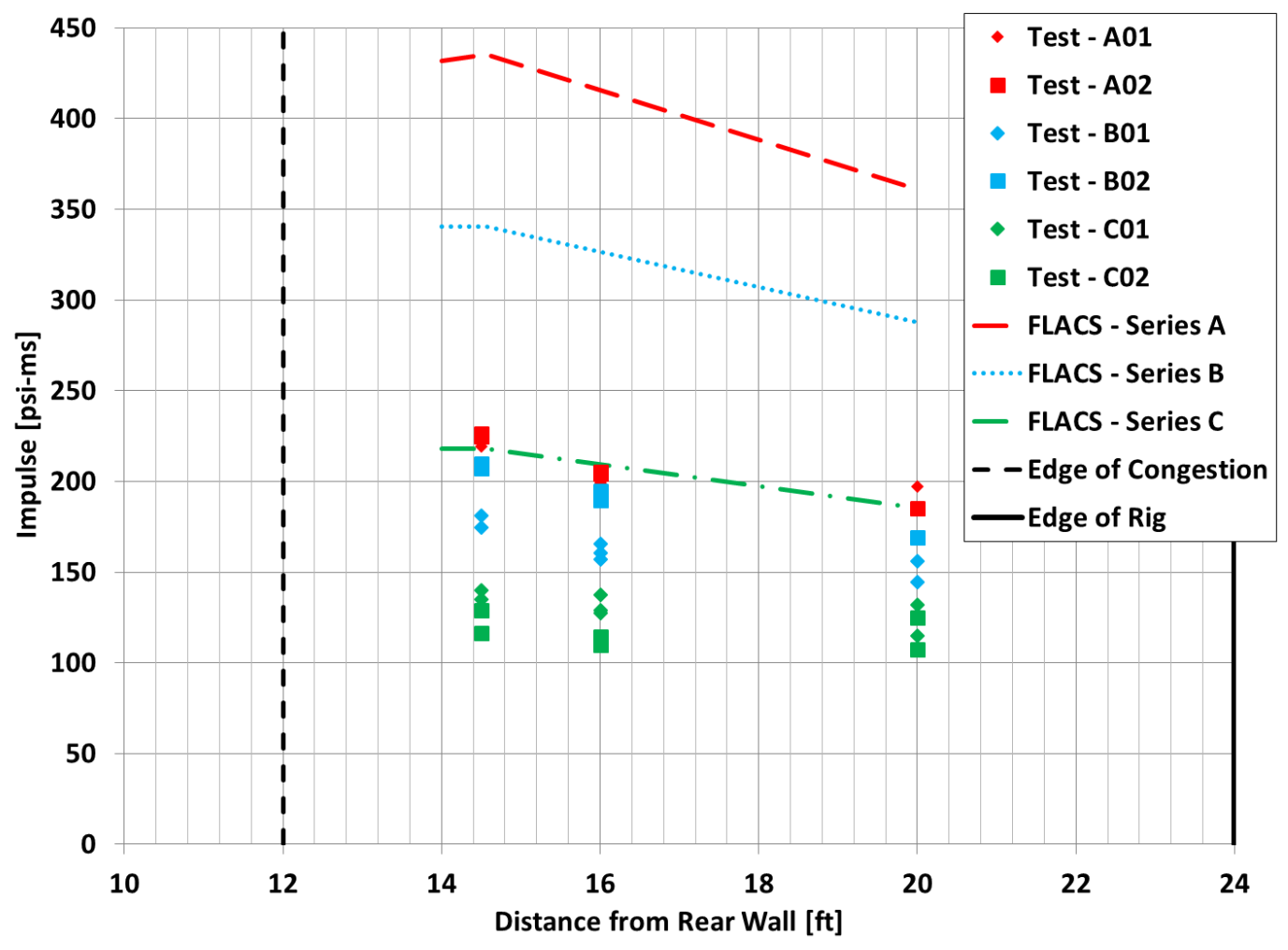

Figure 11. Maximum impulse at the floor for all test series
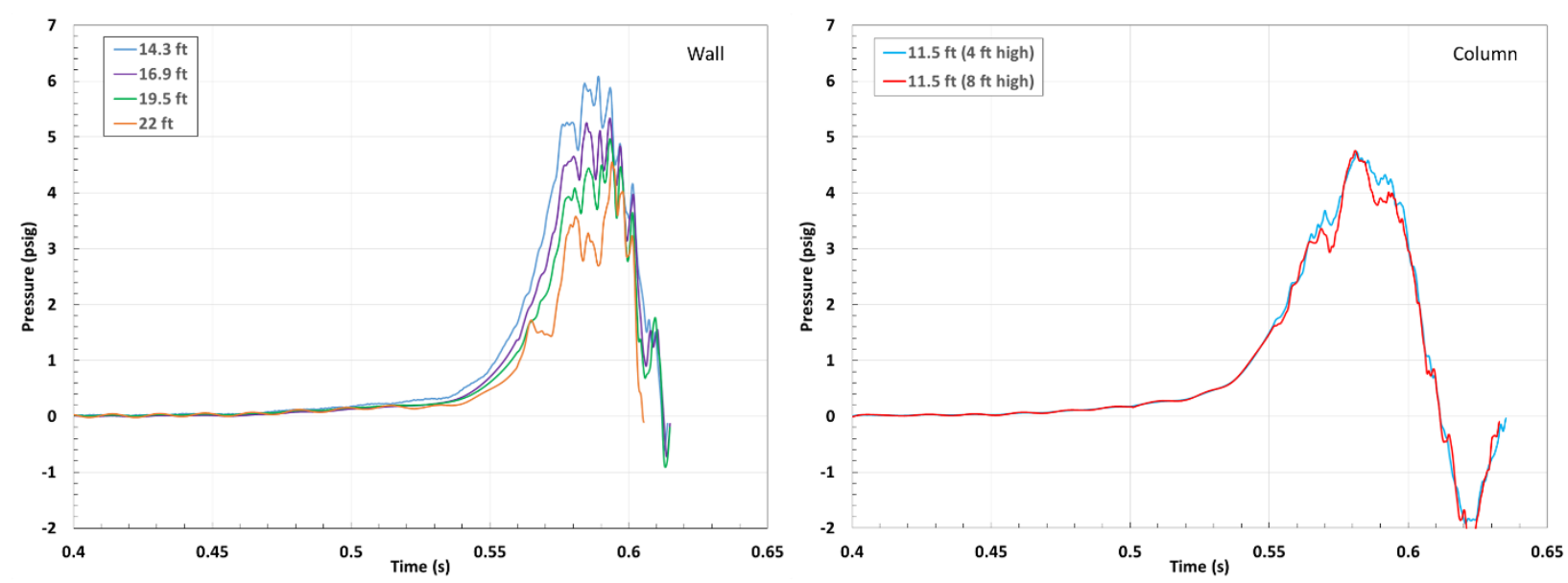

Figure 12. Pressure history at the wall (left) and column (right) pressure transducers (Test A02) 

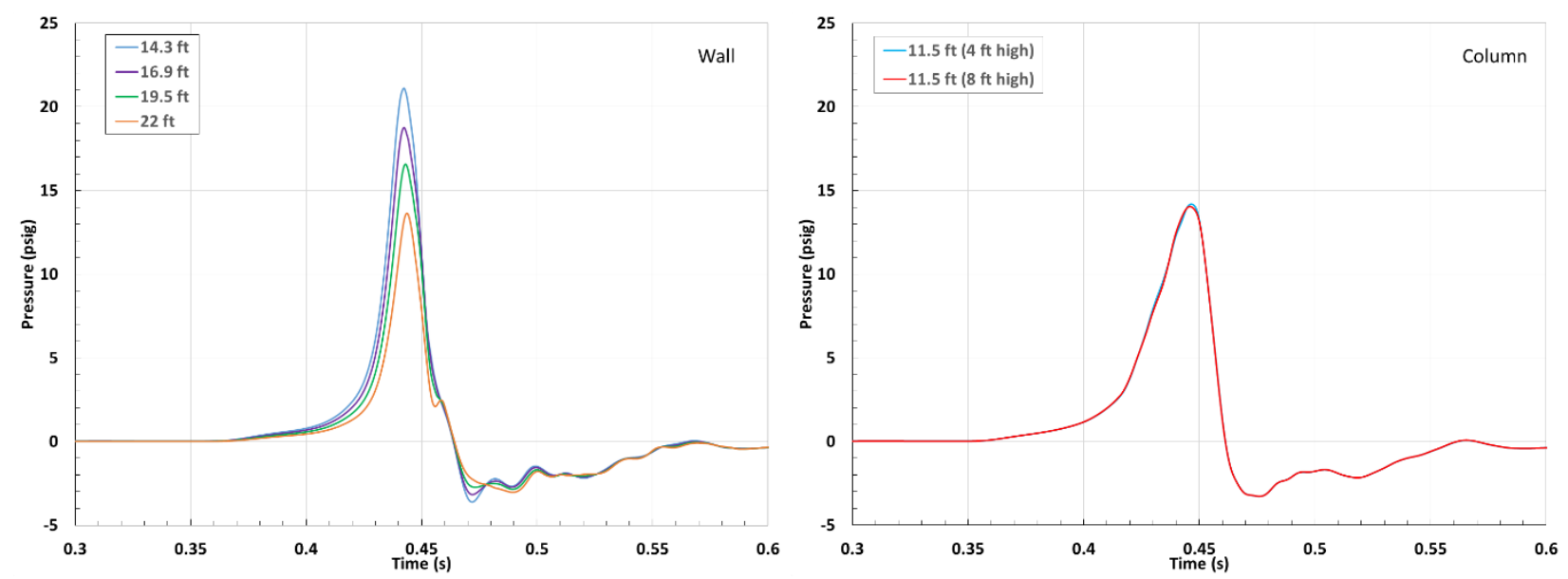

Figure 13. FLACS pressure histories for wall (left) and column (right) transducers for Series A

$\underline{\text { Comparison of internal loads }}$

Average peak pressure and impulse values were calculated based on all internal pressure transducers for each tests series and FLACS simulation. The equivalent duration was then calculated using the average peak pressure and impulse (i.e., duration $=2 \cdot$ impulse/pressure). The average internal peak pressure, impulse, and equivalent duration for all test series are provided in Table 2. The blind FLACS predictions were conservative compared to the test data for both average peak pressure and impulse (i.e., roughly a factor of 2 to 3 ). The FLACS equivalent durations were in fairly good agreement with the test data.

Table 2. Series averages for test data and FLACS simulations

\begin{tabular}{|c|c|c|c|c|c|c|c|c|c|}
\hline \multirow{2}{*}{ Series } & \multicolumn{3}{|c|}{$\begin{array}{c}\text { Peak Pressure } \\
\text { (psig) }\end{array}$} & \multicolumn{3}{c|}{$\begin{array}{c}\text { Impulse } \\
\text { (psi-ms) }\end{array}$} & \multicolumn{3}{c|}{$\begin{array}{c}\text { Equivalent Duration } \\
\text { (ms) }\end{array}$} \\
\cline { 2 - 10 } & $\begin{array}{c}\text { Test } \\
\text { Series }\end{array}$ & $\begin{array}{c}\text { FLACS } \\
\text { Series }\end{array}$ & Ratio & $\begin{array}{c}\text { Test } \\
\text { Series }\end{array}$ & $\begin{array}{c}\text { FLACS } \\
\text { Series }\end{array}$ & Ratio & $\begin{array}{c}\text { Test } \\
\text { Series }\end{array}$ & $\begin{array}{c}\text { FLACS } \\
\text { Series }\end{array}$ & Ratio \\
\hline A & 5.4 & 14 & 2.7 & 204 & 395 & 1.9 & 75 & 55 & 0.7 \\
\hline B & 3.9 & 9.2 & 2.4 & 175 & 314 & 1.8 & 89 & 69 & 0.8 \\
\hline C & 2.0 & 3.9 & 2.0 & 115 & 200 & 1.7 & 114 & 102 & 0.9 \\
\hline
\end{tabular}

The NFPA 68 correlation for venting deflagrations of gas mixtures was used to predict the internal peak pressure and duration for each test series. The internal peak pressure and duration were then used to determine the corresponding impulse. The average peak pressures internal to the test rig for all test series are shown in Figure 14 along with those predicted by the FLACS simulations and NFPA 68. The internal impulse for each test series is shown in Figure 15, along with those predicted by the FLACS simulations and NFPA 68. Previous work comparing internal peak pressure data from the DLG to NFPA 68 predictions [4] discussed the limitations of NFPA 68 for accounting for varying levels of congestion at $A_{r}$ ratios of less than 0.4. For Test Series $B$ and $\mathrm{C}$, the $\mathrm{A}_{\mathrm{r}}$ ratio is less than 0.4 ( 0.32 and 0.17 for Test Series B and C, respectively), and this causes the NFPA 68 predictions to be identical for these two series. 
For all test series, the NFPA 68 predicted peak pressures are lower than the test data, as well as the FLACS predictions. The NFPA 68 calculated impulse, along with the internal FLACS impulse predictions were conservative for all test series.

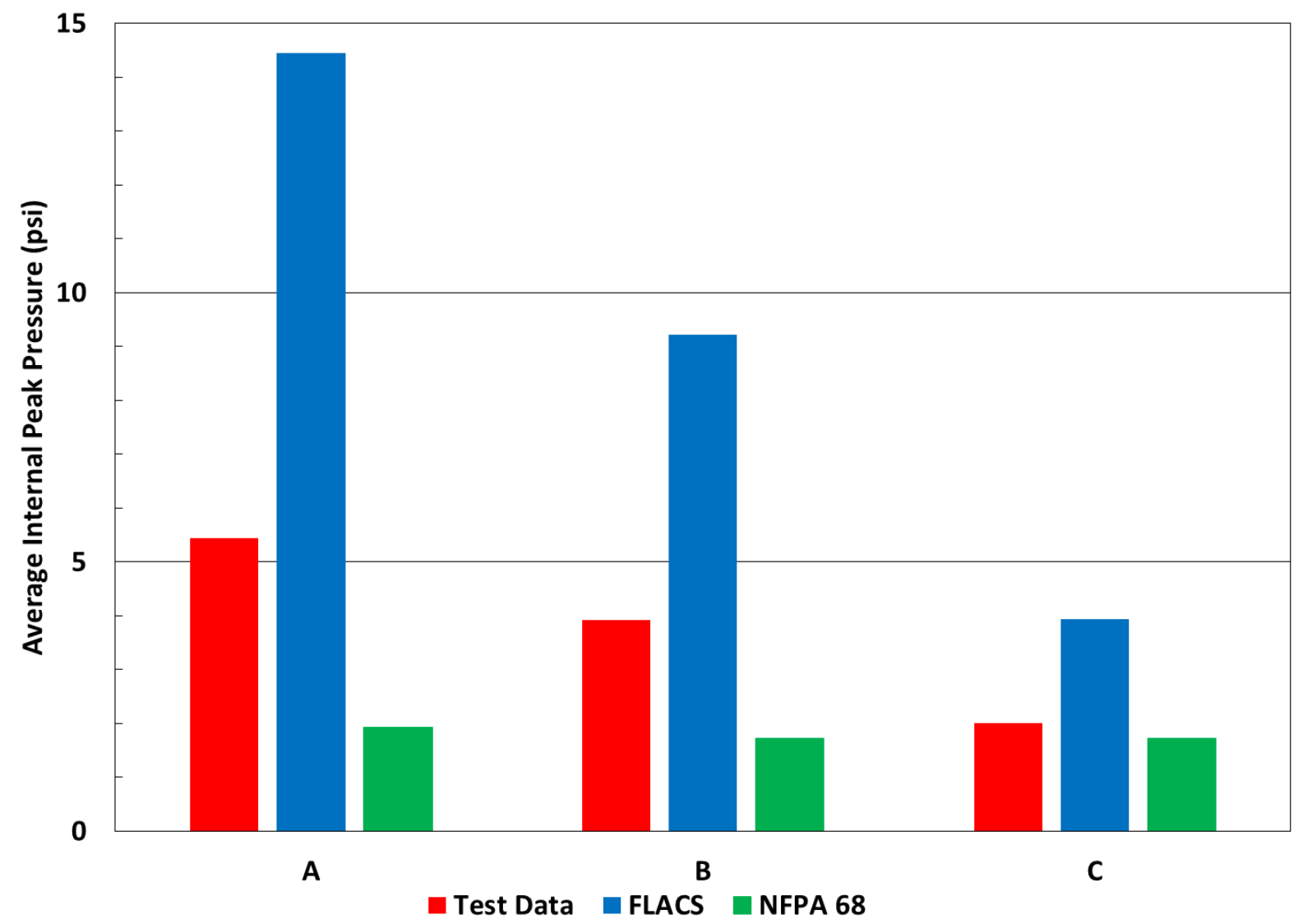

Figure 14. Average internal peak pressure compared to FLACS simulations and NFPA 68 


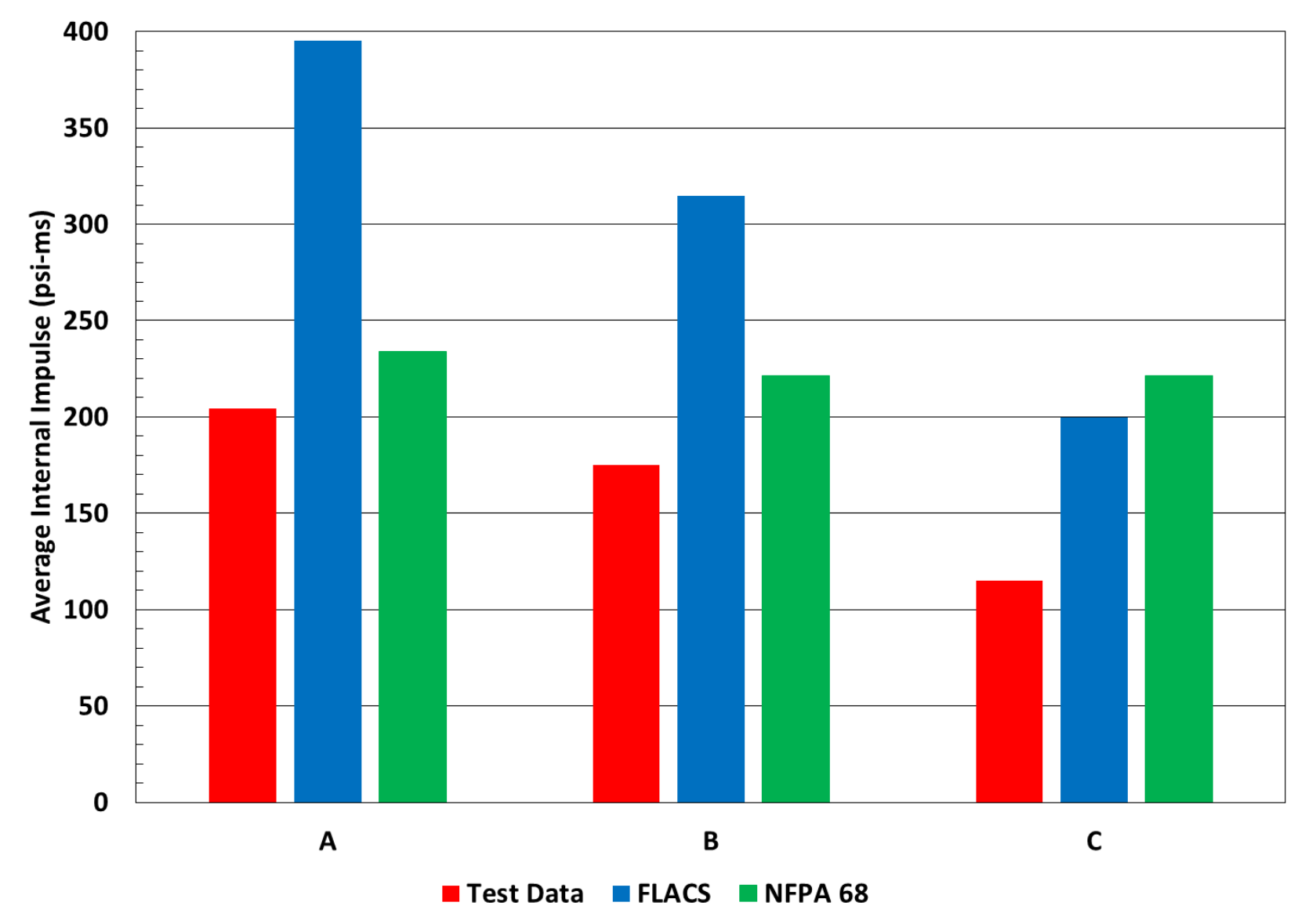

Figure 15. Average internal impulse compared to FLACS simulations and NFPA 68

\section{External pressure}

External pressure and impulse measurements were also recorded for all tests. Exemplar pressure traces from test A02 (ABR 11\%, VBR 0.5\%) are provided in Figure 16. Figure 17 shows exemplar FLACS simulation pressure traces for Test Series A at the same locations. External to the DLG, the FLACS simulation predicted pressure wave trends are similar to those for the test data. The external pressure and impulse measurements for all test series and FLACS simulations are provided in Figure 18 and Figure 19, respectively. The external peak pressure and impulse (duration) measurements decreased as the congestion inside the DLG was decreased (i.e., from Test Series A to B and from Test Series B to C). Similar to the internal data, the FLACS peak pressure and impulse predictions external to the rig were conservative. 


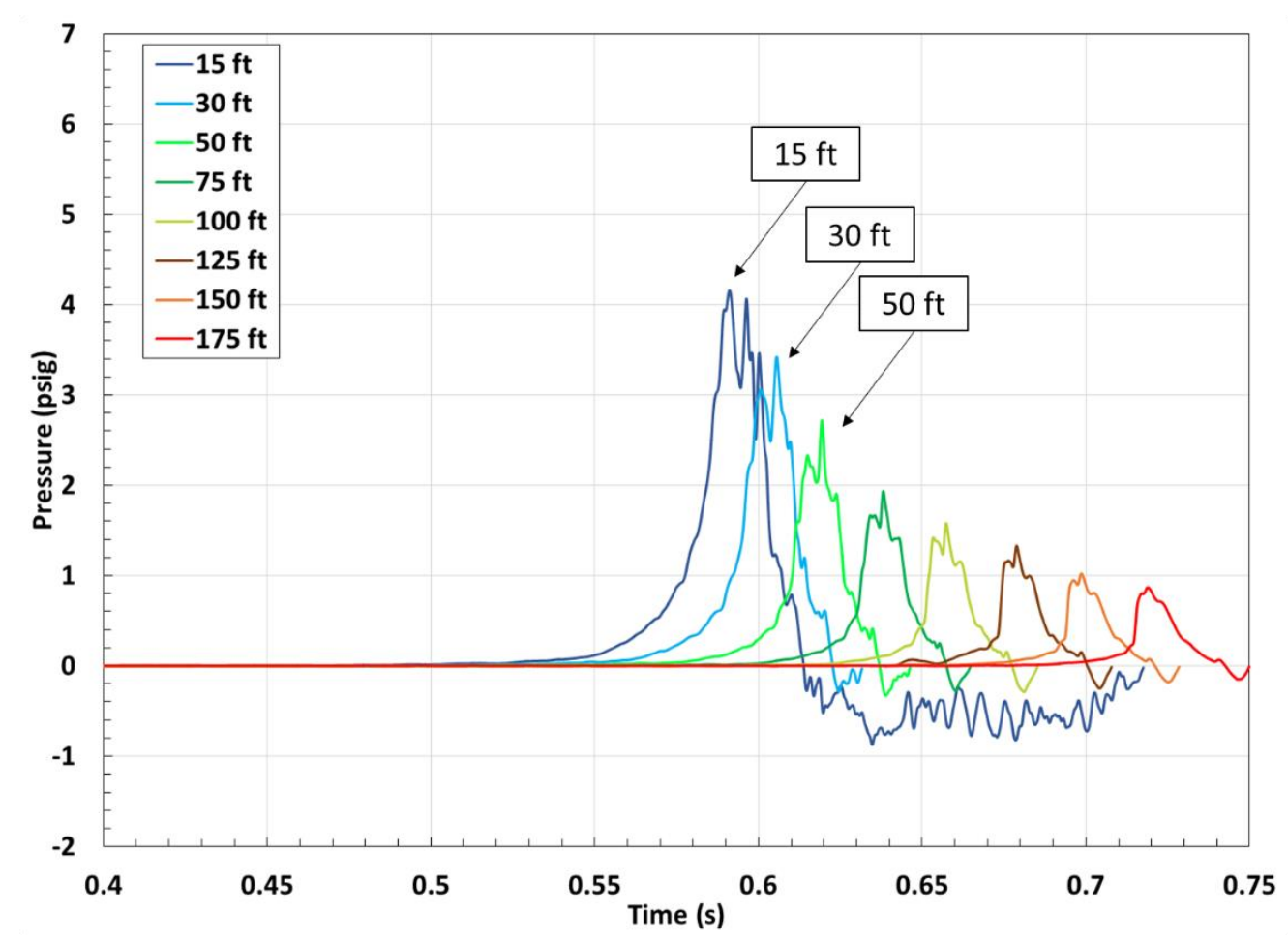

Figure 16. Pressure history external to the test rig for Test A02

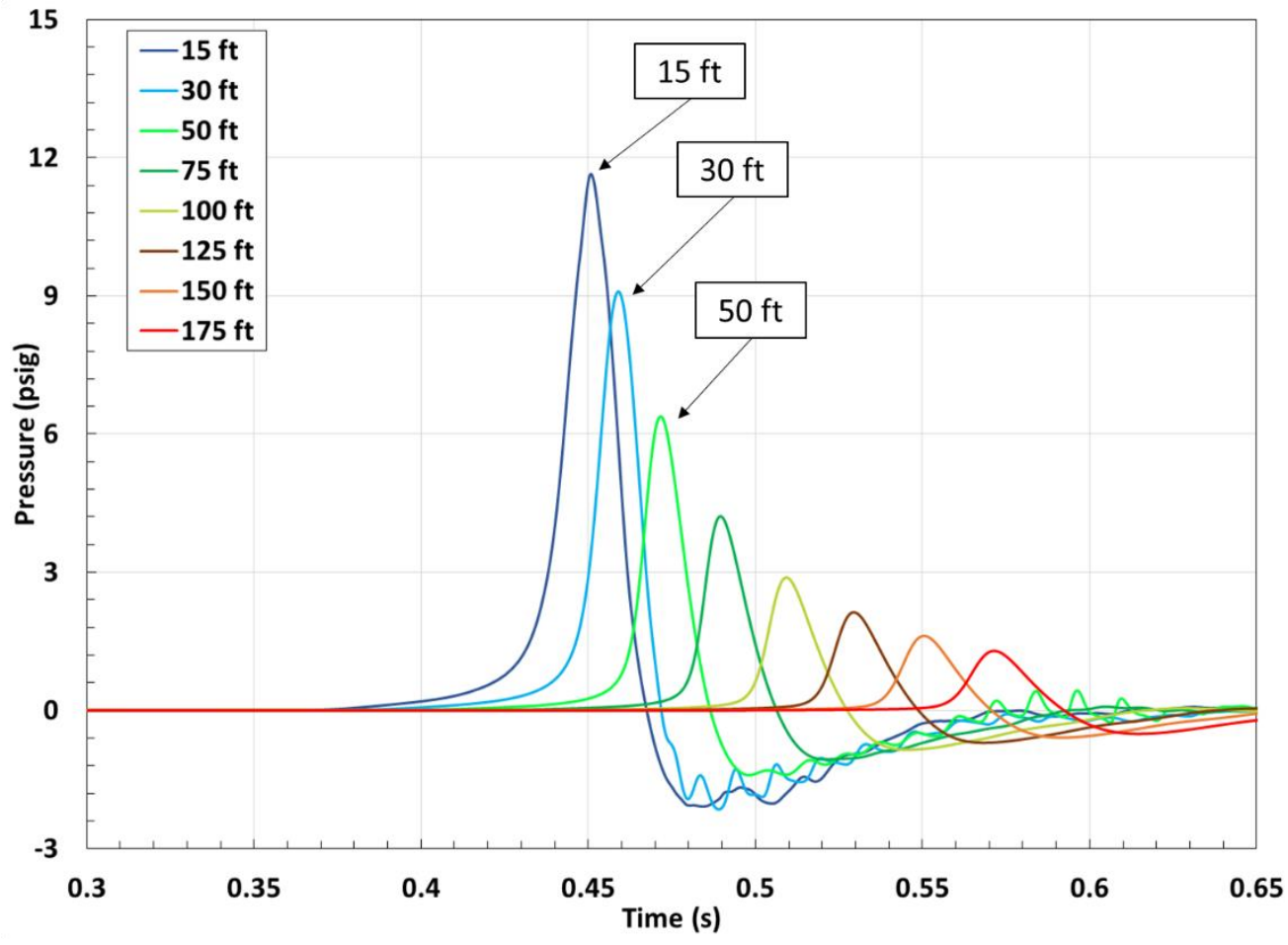

Figure 17. FLACS predicted pressure history external to the test rig for Test Series A 


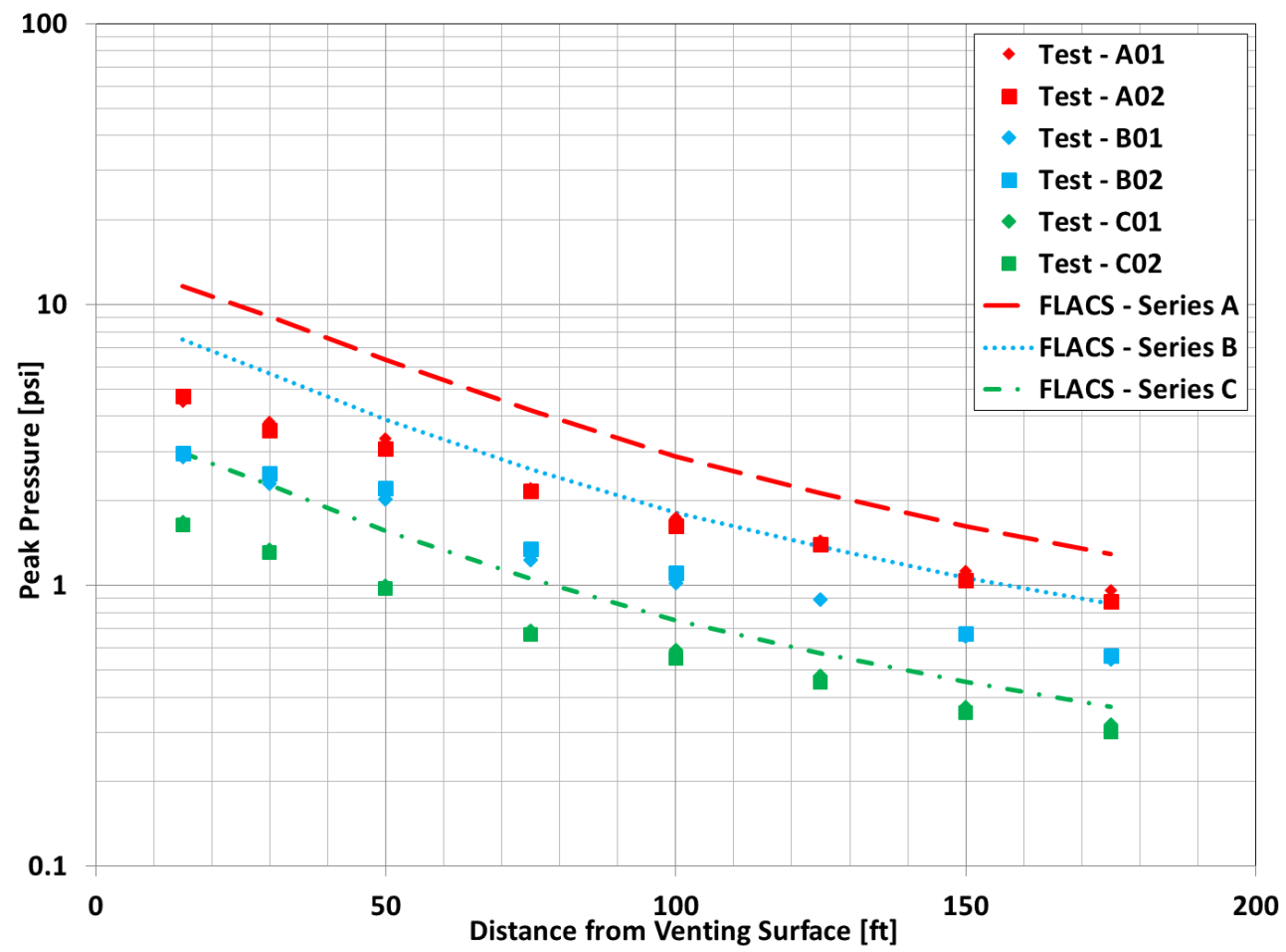

Figure 18. External peak pressure for all test series and FLACS simulations

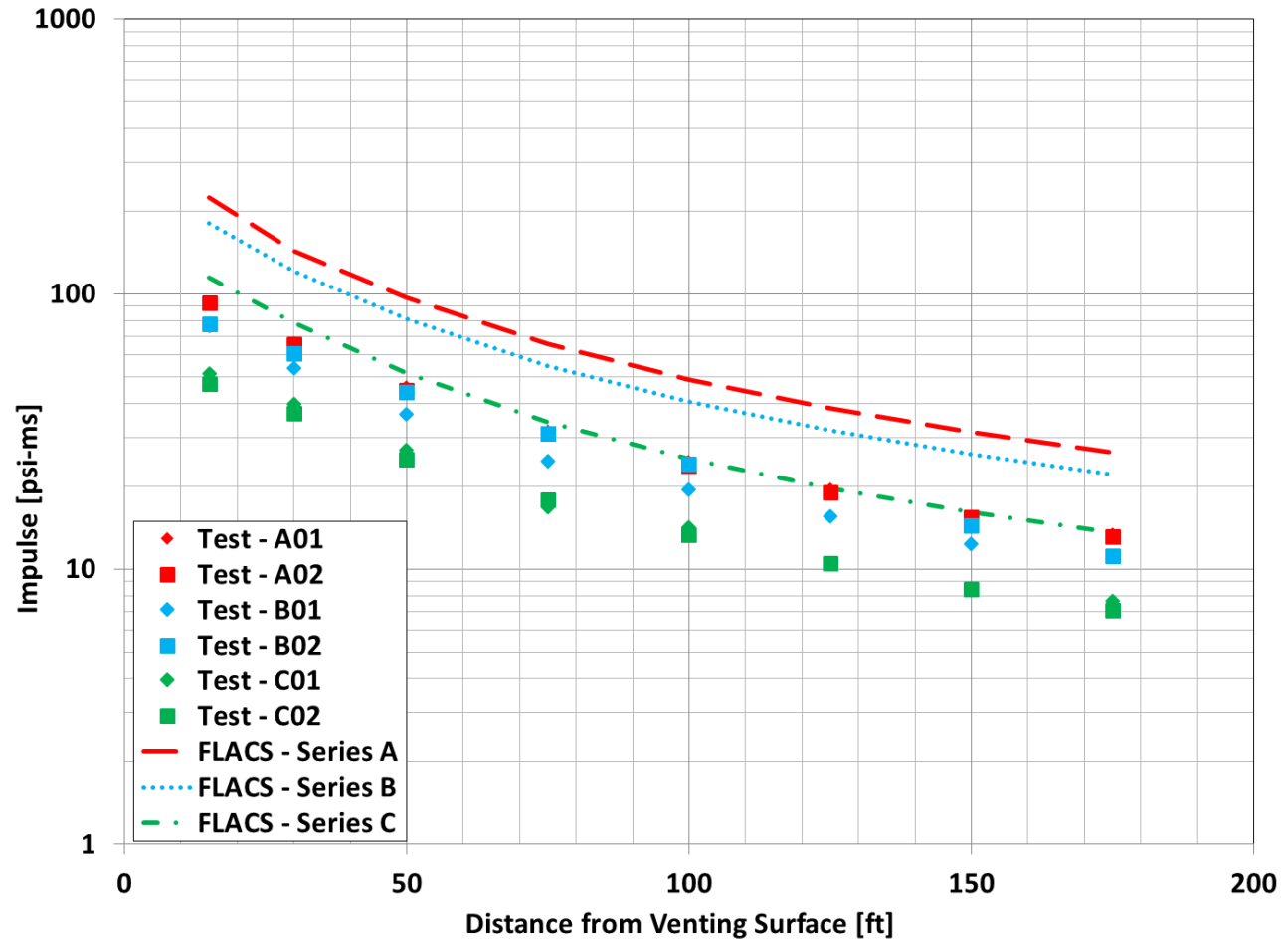

Figure 19. External impulse for all test series and FLACS simulations 


\section{Conclusions}

This test program was conducted to determine the peak deflagration pressure achieved within a partially congested enclosure vented through one wall. The test data was compared to the predictions made using the FLACS CFD code and the NFPA 68 correlations. Internal to the DLG, the FLACS-predicted wave shape and duration matched well with the test data, however the peak pressures were conservative compared to the test data by a factor of approximately 2 to 3 , depending on the location inside the rig and the test series. NFPA 68 internal peak pressure predictions were also compared to the test data. The NFPA 68 internal peak pressure predictions were not conservative for all test series.

Peak pressure, impulse (duration) and wave shape were evaluated inside the DLG in the region where test specimens would be located during equipment qualification testing. In the configurations tested during this program, centrally-peaked blast loads of up to 5.4 psig and 230 psi-ms were demonstrated. Blast loading was found to be reasonably symmetrical across the rig. Higher congestion levels in the rear half of the rig would yield higher blast pressures than those demonstrated during this program. It is expected that shifting the ignition source forward, away from the rear wall, would increase the blast load duration.

External peak pressure and impulse measurements were shown to decrease when the internal congestion was decreased, which is due to the decrease in the overall energy release rate. Similar

to the internal data, the FLACS peak pressure and impulse predictions external to the rig were conservative.

\section{Acknowledgments}

The test program described in this paper was performed as a BakerRisk Internal Research (IR) project. The VCE tests described in this paper were carried out with the help and support of Darren Malik, Brad Horn, Emiliano Vivanco, Jack Beadle, Corbin McCollough, Nolan Payne, Greyson Thompson, and David Tighe; their contributions to this work are also acknowledged.

\section{References}

1. National Fire Protection Association, Standard on Explosion Protection by Deflagration Venting, NFPA 68 (2013 Edition), Quincy, MA.

2. Center for Chemical Process Safety (CCPS), Guidelines for Vapor Cloud Explosion, Pressure Vessel Burst, BLEVE and Flash Fire Hazards, August 2010

3. Gexcon AS, "FLACS v10.3 User's Manual" (2014)

4. Diakow, P. A., Thomas, J. K., Parsons, P. J., Large-Scale Vented Deflagration Tests, Mary Kay O’Connor Process Safety Center International Symposium, October 2016 